South African Journal of Geomatics, Vol. 4, No. 3, August 2015

\title{
Fire scar mapping for disaster response in KwaZulu-Natal South Africa using Landsat 8 imagery
}

\author{
Zakariyyaa Oumar \\ KZN Department of Agriculture and Rural Development, South Africa, Zak.Oumar@kzndard.gov.za
}

DOI: http://dx.doi.org/10.4314/sajg.v4i3.11

\begin{abstract}
This study assessed the potential of the new Landsat 8 multispectral imagery in rapidly mapping fire scars to aid disaster management response teams in emergency efforts. Maximum likelihood and iso cluster algorithms where used to classify burnt and unburnt areas in KwaZulu-Natal, South Africa. The Landsat 8 sensor successfully classified burnt and unburnt areas with overall accuracies ranging from $80 \%$ to $93.33 \%$ on independent test datasets. Farms and communities affected by the wildfires were overlaid with the classified maps in order to determine the extent of each farm burnt. Maps were created for disaster management response teams in order to identify critical farms and communities in need of assistance. The study indicates the operational use of the new Landsat 8 data in fire scar mapping for disaster response. The result is critical for fire scar mapping in South Africa using freely available Landsat 8 multispectral data.
\end{abstract}

\section{Introduction}

The mapping of fire scars plays an important role in the disaster management cycle and forms part of the response and recovery stages of disaster management (Joyce et al., 2009). The ability to rapidly determine the location of burnt areas and the people affected is essential to ensure that emergency services and disaster management teams reach the areas affected in a timely manner. Remote sensing technology paves the way for this demand by using earth monitoring satellites to locate and map fire scars rapidly and this information is then relayed to emergency services in the event of a natural disaster (Joyce et al., 2009). Space and airborne sensors have been used to map burnt areas, assess characteristics of active fires, and characterize post-fire ecological effects (Bastarrika et al., 2011; Hudak and Brockett, 2004; Lentile et al., 2006). Burnt vegetation and organic matter generally results in optically darker scar features in imagery due to the presence of ash thereby resulting in different reflectance values as compared to unburnt surfaces (Joyce et al. 2009). These reflectance differences are then used to separate burnt and unburnt areas using individual spectral bands, normalized indices and band ratios (Trigg et al., 2005). In satellite sensors with a spatial resolution of 30 metres and above, burnt vegetation results in a reduction in the visible to near-infrared reflectance $(400-1300 \mathrm{~nm})$ associated with the charring and removal of vegetation (Eva and Lambin, 1998; Trigg and Flasse 2000). At finer spatial resolutions of less than 5 metres, burnt vegetation can cause a rise in surface reflectance thereby resulting in a rise in the short wave infrared reflectance $(1600-2500 \mathrm{~nm})$ due to the deposition of white ash (Landmann, 2003; Roy and Landmann, 2005). The utility of using moderate or fine scale data in assessing fire damage depends largely on the scale of the application. Higher spatial resolution data which is often costly is used for the prediction of areas likely to burn, suppression as fires burn and post fire rehabilitation efforts (Lentile et al., 2006). Moderate resolution data such as Landsat is used to quantify the areas burnt, separate burnt from unburnt areas, and has more local applicability (Bastarrika, 2011; Lentile et al., 2006). With the free availability of the new Landsat 8 data which was launched in February 2013, remote sensing researchers in Africa are able to assist emergency response services in wildfire mapping which is one of the major disasters facing African countries (Guha-Sapir, et al., 2014).

KwaZulu-Natal is the province that has the highest risk of wild fires in South Africa with an average of 200000 ha of veld burns on an annual basis (Mans, 2014). The province has a fire frequency of 1:4 years meaning it can experience a significantly higher than average fire season once in every four years (Mans, 2014). On the $15^{\text {th }}$ of June 2014, 26 wild fires were reported on farms in the area. The spread of these fires were rapid due to the intensity of the gale force winds which averaged at 42 kilometres per hour. The speed of these fires combined with the fuel loads made it difficult to stop the fire with conventional methods using the fire department trucks, working on fire teams, and community members (Mans, 2014). There was an urgent need to identify the farms and communities affected by these fires in order to send disaster management teams to offer support and aid to the affected communities. Traditional techniques such as heads up digitizing have been used successfully in mapping burn scars using medium to high resolution imagery such as Synthetic Aperture Radar (SAR) (Bourgeau-chavez et al., 2002). However, these techniques are time consuming, subjective and cannot be used in rapid emergency response situations. Quick classification techniques such as supervised and unsupervised algorithms which rapidly identifies burnt and unburnt pixels plays a more pivotal role in disaster response emergency situations. This paper assessed the potential of the freely available new Landsat 8 multispectral data in rapidly mapping burnt areas using traditional classification algorithms. The study also identified farms and communities affected by the wild fire in order to assist emergency services in disaster response. 


\section{Study Area}

KwaZulu-Natal covers an area of approximately $94383 \mathrm{~km}^{2}$ of which 6.5 million ha is used for farming. Vegetation of KwaZulu-Natal is predominantly grassland and savannah. Rainfall ranges from about 600 to $1400 \mathrm{~mm}$ per annum with mainly higher rainfall $(>1000 \mathrm{~mm})$ in the summer months. Mean annual temperature ranges from about $10^{\circ}$ to $24^{\circ}$ C. These conditions promote faster growth of grasses and hence accumulate enough biomass every summer season which increases the risk of fires in the province (Mans, 2014). Figure 1 shows a map of the study area.

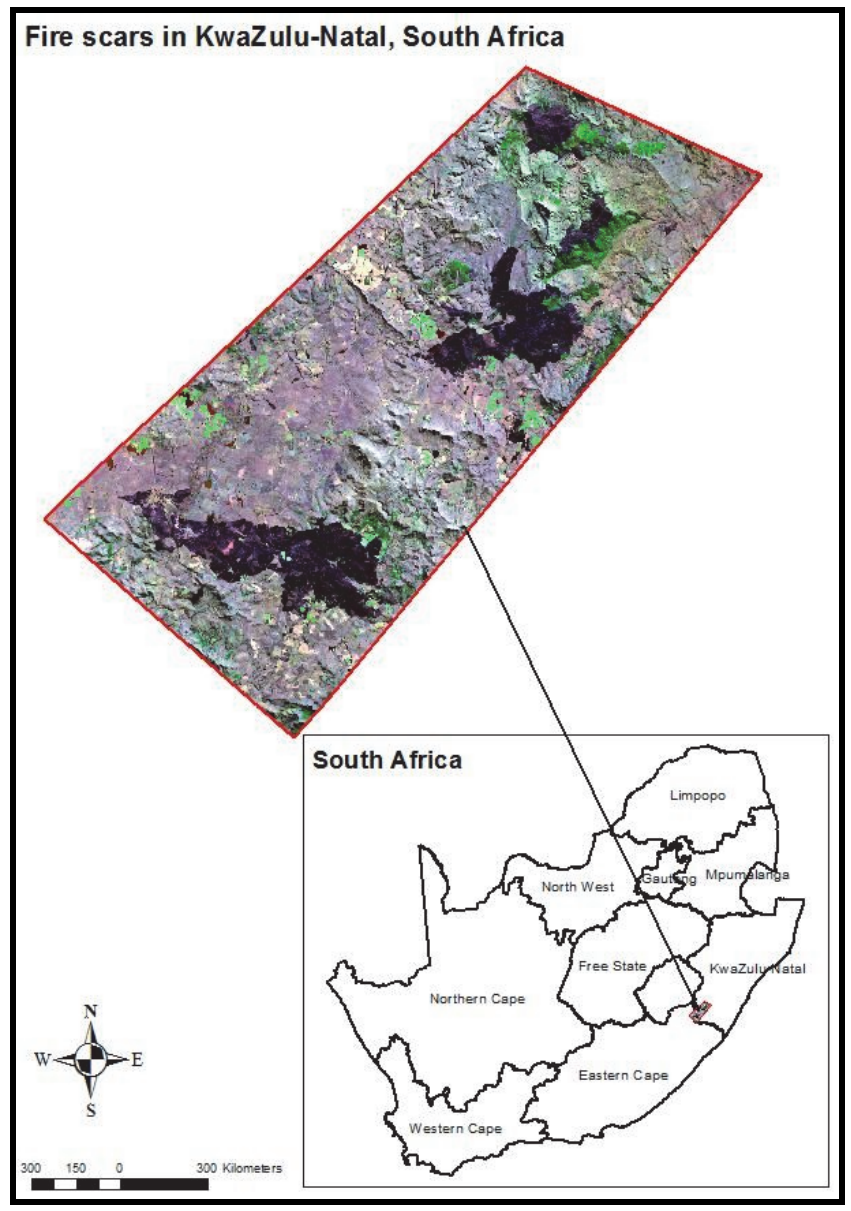

Figure 1. Map of the study area

\section{Methods}

\subsection{Landsat 8 imagery}

One scene of Landsat 8 multispectral data covering the wildfires was acquired on the $16^{\text {th }}$ of June 2014 from the United States Geological Survey (USGS). The scene was atmospherically and geometrically corrected by the data providers and projected to the UTM Zone 35 S (WGS84) coordinate system. The top of atmosphere reflectance for bands 1-9 had an absolute radiometric uncertainty of less than 3\% and a geodetic pixel uncertainty of less than $12 \mathrm{~m}$ at the $90 \%$ confidence level. Landsat 8 Operational Land Imager (OLI) and Thermal Infrared Sensor (TIRS) data consists of 9 spectral bands. Bands 10 and 11 are the thermal bands which are used for surface temperature estimates and are collected at 100 metres (USGS, 2014). The temporal cycle of the Landsat 8 scenes are every 16 days and images are available for immediate download once processing is complete which takes 3 days. The spectral and spatial resolution of the Landsat 8 sensor is shown in Table 1. 
South African Journal of Geomatics, Vol. 4, No. 3, August 2015

Table 1. Spectral and spatial resolution of Landsat 8

\begin{tabular}{lcc}
\hline \multicolumn{1}{c}{ Bands } & Spectral Range (micrometres) & Resolution (metres) \\
\hline 1- Coastal aerosol & $0.43-0.45$ & 30 \\
2- Blue & $0.40-0.51$ & 30 \\
3- Green & $0.53-0.59$ & 30 \\
4- Red & $0.64-0.67$ & 30 \\
5- Near Infrared (NIR) & $0.85-0.88$ & 30 \\
6- Shortwave Infrared 1 & $1.57-1.65$ & 30 \\
7- Shortwave Infrared 2 & $2.11-2.29$ & 30 \\
8-Panchromatic & $0.50-0.68$ & 15 \\
9-Cirrus & $1.36-1.38$ & 30 \\
10-Thermal Infrared (TIRS) 1 & $10.60-11.19$ & 100 \\
11-Thermal Infrared (TIRS) 2 & $11.50-12.51$ & 100 \\
\hline
\end{tabular}

\subsection{Sampling}

A random set of sixty points $(\mathrm{n}=60)$ were generated over the multispectral image covering burnt and unburnt areas as shown in Figure 2. The point dataset was divided into two sets whereby thirty points were used for training $(\mathrm{n}=30)$ the image and the remaining thirty points were used for validating the performance of the classification $(n=30)$.

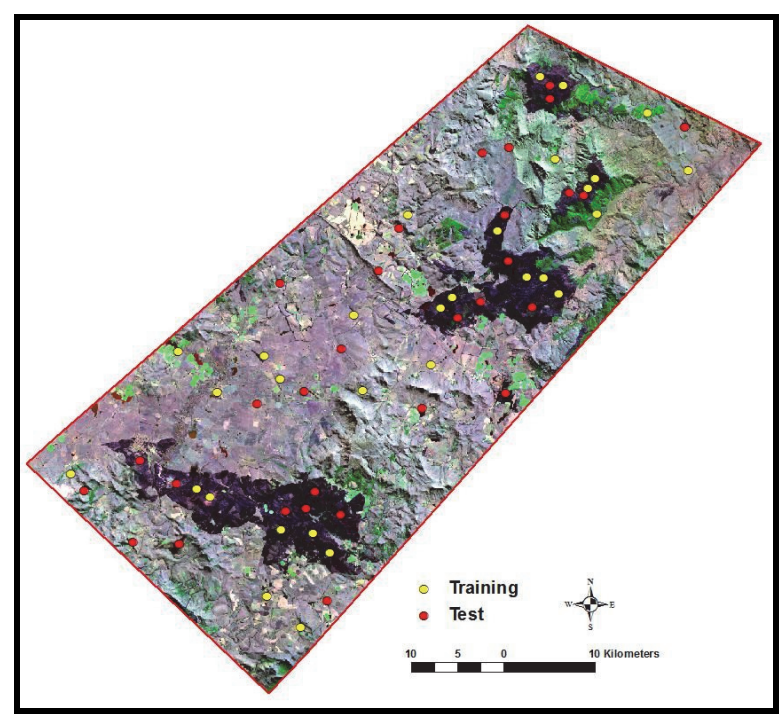

Figure 2. Training and test samples $(n=60)$

\subsection{Supervised classification}

Training signatures were taken from the pan sharpened image of the Landsat 8 data which clearly shows burnt and unburnt areas. Signatures were created for two classes (burnt verses unburnt). A maximum likelihood classification algorithm was used to classify the image. Maximum likelihood is one of the most common classifiers used in remote sensing studies and assumes that the spectral values of training pixels are normally distributed (Bastarrika et al., 2011). The algorithm is based on the Bayesian theorem of decision making and utilizes the variance and covariance of the training signatures to assign a specific class. Each pixel is then assigned to a class which it has the highest probability of being a member (ESRI, 2010).

\subsection{Unsupervised classification}

The utility of an unsupervised classification algorithm in mapping burnt and unburnt areas using the Landsat 8 scene was also tested. The iso cluster algorithm uses an iterative optimization clustering procedure which separates cells into a user specified number of distinct classes. The process starts by the software assigning arbitrary means to each of the user defined clusters. During each iteration samples are assigned to the closest means based on the attribute distances of 
the cells that belong to a cluster. This process is repeated and the means are recalculated after each iteration. Each pixel is then assigned to the closest mean in multidimensional attribute space (ESRI, 2010). Only two clusters were selected for the iso cluster algorithm to separate burnt and unburnt areas.

\subsection{Classification accuracy}

In order to evaluate the performance of the supervised and unsupervised classification algorithms, the confusion matrix was constructed using the independent test dataset $(n=30)$. The confusion matrix was used to compare the true class with the class assigned by the classifier and to calculate the overall accuracy as well as the user and producer accuracy. The user accuracy is calculated by dividing the number of correctly classified pixels by the total number of pixels that were classified in that particular class, and is represented by the row total in the confusion matrix. Producers accuracy is computed by dividing the number of correctly classified pixels in each class by the number of training data used for that particular class, and is expressed by the column total in the confusion matrix (Congalton and Green, 1999). Furthermore the kappa analysis which uses the $k$ (KHAT) statistic was used to determine and compare significant differences between burnt and unburnt areas. If the $k$ statistic coefficients are equal to or close to 1 , there would be perfect agreement between the percentage of correct values of an error matrix and the actual agreement in the error matrix (Prasad et al., 2006).

\subsection{Identifying farms and communities affected}

Once the burn scars were classified, the 2014 surveyor general's cadastral dataset was overlaid on the burn scars to identify farms and communities affected by the fire. The percentage of each farm burnt was then calculated. The maps were then given to disaster response teams to aid in their emergency efforts.

\section{Results and Discussion}

\subsection{Mean Burnt Reflectance}

The mean reflectance of the burnt pixels are shown in Figure 3. There is a decrease in reflectance in the visible and near-infrared bands and an increase in the shortwave infrared bands. This sudden decrease in reflectance in the visible and near-infrared bands and increase in the shortwave infrared bands is due to the replacement of healthy senesced vegetation by char which is picked up by Landsat bands 3, 4, 5 and 7 which contain most of the spectral information for burn scars (Pereira and Setzer, 1993; Trigg and Flasse, 2000).

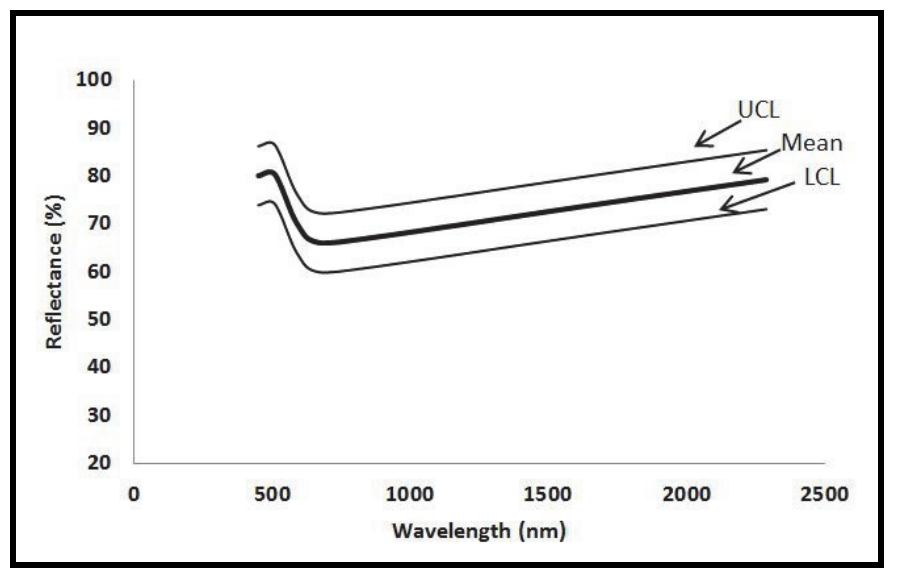

Figure 3. Mean burnt reflectance of Landsat 8 bands. The mean, 95\% upper confidence limit (UCL), and 95\% lower confidence limit (LCL) of the reflectance are shown

\subsection{Classifying burnt and unburnt areas}

The confusion matrix in Table 2 indicates the performance of the maximum likelihood algorithm in classifying burnt and unburnt areas using the independent test dataset. The high overall classification accuracy of $93.33 \%$ and $k$ statistic of 0.87 indicates the strong performance of the maximum likelihood classification algorithm. Both the user and producer accuracies were relatively high at $93.33 \%$. The confusion matrix in Table 3 indicates the performance of the iso cluster algorithm in classifying burnt and unburnt areas using the independent test dataset. The iso cluster yielded an overall classification accuracy of $80 \%$ with a $k$ statistic of 0.60 . The producer accuracy was relatively high at $90.91 \%$ whereas the user accuracy was at $66.67 \%$. The classified maps of the fire scars are shown in Figure 4. 
South African Journal of Geomatics, Vol. 4, No. 3, August 2015

Table 2. Maximum likelihood confusion matrix

\begin{tabular}{cccc}
\hline Classes & Burnt & Unburnt & Row total \\
\hline Burnt & 14 & 1 & 15 \\
Unburnt & 1 & 14 & 15 \\
Column total & 15 & 15 & 30 \\
Producer accuracy & $=93.33 \%$ & Overall accuracy & $=93.33 \%$ \\
User accuracy & $=93.33 \%$ & Kappa & $=0.87$ \\
\hline
\end{tabular}

Table 3. Iso cluster confusion matrix

\begin{tabular}{cccc}
\hline Classes & Burnt & Unburnt & Row total \\
\hline Burnt & 14 & 1 & 15 \\
Unburnt & 5 & 10 & 15 \\
Column total & 19 & 11 & 30 \\
Producer accuracy & $=90.91 \%$ & Overall accuracy & $=80.00 \%$ \\
User accuracy & $=66.67 \%$ & Kappa & $=0.60$ \\
\hline
\end{tabular}

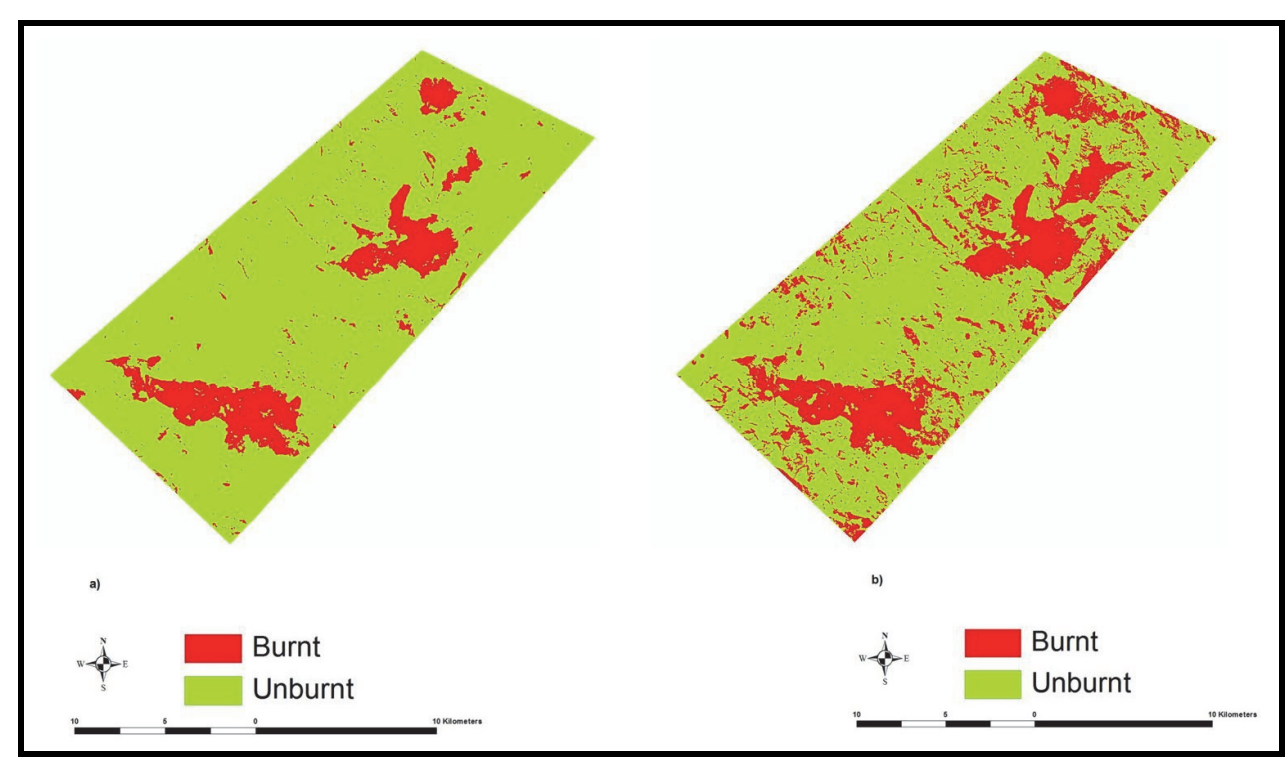

Figure 4. a) Maximum likelihood classification b) Iso cluster classification

The results show the capability of the new Landsat 8 sensor in successfully mapping fire scars with overall accuracies ranging from $80 \%$ to $93.33 \%$ using traditional unsupervised and supervised classification algorithms respectively. Similar results were obtained by Petropoulos et al., (2012) who used maximum likelihood, support vector machines and artificial neural networks to delineate burnt areas using Landsat TM imagery and got accuracies ranging from $86.18 \%$ to $93.55 \%$. Bastarrika et al., (2011) also received high accuracies with kappa values of 0.85 in delineating burned perimeters in Portugal and Southern California using Landsat TM images. However these results were based on old Landsat TM imagery in mapping burnt areas and were not tested on the latest Landsat 8 mission. The results from this study show the applicability of the newer Landsat 8 bands in successfully mapping burnt areas to aid in disaster management efforts.

\subsection{Identifying Farms Affected}

There were 45 farms that were affected by the wildfires with the percentage of individual farm burns ranging from $13 \%$ to $99.7 \%$. Figure 5 shows the farms affected by the wildfires using the more accurate maximum likelihood classification map. The percentage of each farm burnt is shown in Table 4. 


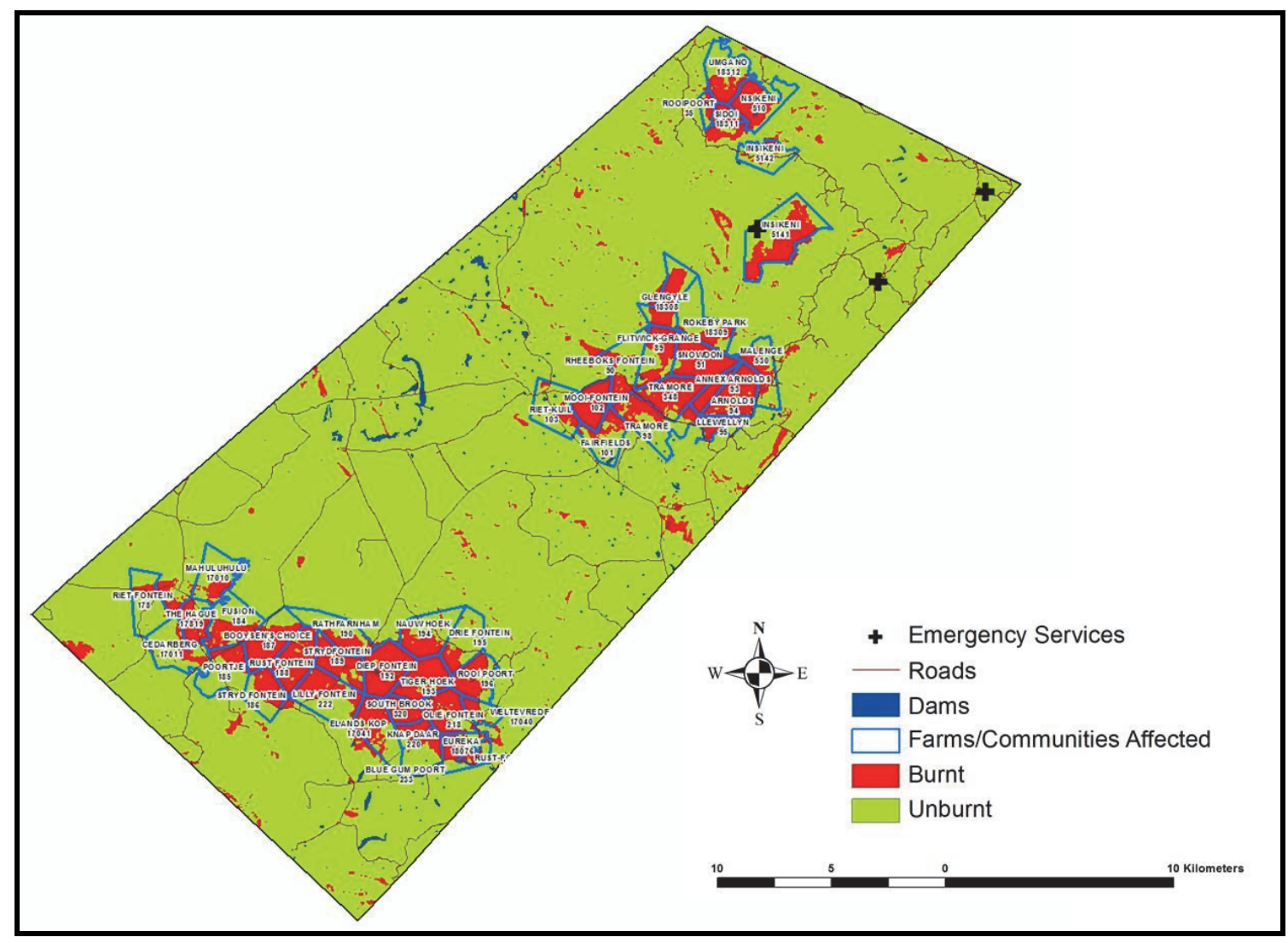

Figure 5. Farms affected based on the Maximum likelihood classification

Table 4. Percentage of each farm burnt

\begin{tabular}{lccc}
\hline Farm name & Farm area (ha) & Burnt area (ha) & Percentage of farm burnt \\
\hline Annex arnolds 93 & 443.6 & 442.1 & 99.7 \\
Arnolds 94 & 1204.2 & 1103.6 & 91.6 \\
Blue gum poort 233 & 956.5 & 306.0 & 32.0 \\
Booysen's choice 187 & 1357.8 & 1064.1 & 78.4 \\
Cedarberg 17011 & 1391.8 & 245.2 & 17.6 \\
Diep fontein 192 & 1327.9 & 1318.7 & 99.3 \\
Drie fontein 195 & 1184.3 & 330.1 & 27.9 \\
Elands kop 17041 & 1372.8 & 826.1 & 60.2 \\
Eureka 18076 & 332.4 & 159.4 & 48.0 \\
Fairfields 101 & 1022.2 & 417.5 & 40.8 \\
Flitwick-grange 89 & 1223.9 & 519.7 & 42.5 \\
Fusion 184 & 1396.2 & 607.1 & 43.5 \\
Glengyle 18308 & 1193.3 & 760.3 & 63.7 \\
Insikeni 5141 & 2373.6 & 1238.2 & 52.2 \\
Insikeni 5142 & 828.1 & 187.5 & 22.6 \\
Knap daar 220 & 405.0 & 321.3 & 79.3 \\
Lilly fontein 222 & 1633.6 & 883.6 & 54.1 \\
Llewellyn 95 & 541.3 & 396.0 & 73.2 \\
Mahuluhulu 17010 & 1203.1 & 270.6 & 22.5 \\
\hline
\end{tabular}


South African Journal of Geomatics, Vol. 4, No. 3, August 2015

\begin{tabular}{lccl}
\hline Malenge 530 & 1067.7 & 510.8 & 47.8 \\
Mooi-fontein 102 & 883.5 & 864.8 & 97.9 \\
Nauw hoek 194 & 1348.9 & 621.5 & 46.1 \\
Nsikeni 510 & 1226.9 & 859.6 & 70.1 \\
Olie fontein 218 & 1104.8 & 867.5 & 78.5 \\
Poortje 185 & 1294.2 & 411.6 & 31.8 \\
Rathfarnham 190 & 1233.9 & 485.2 & 39.3 \\
Rheeboks fontein 90 & 1174.7 & 806.7 & 68.7 \\
Riet fontein 178 & 1209.1 & 157.0 & 13.0 \\
Riet-kuil 103 & 1290.2 & 333.1 & 25.8 \\
Rokeby park 18309 & 1352.5 & 400.0 & 29.6 \\
Rooi poort 196 & 1014.9 & 688.0 & 67.8 \\
Rooipoort 35 & 285.2 & 179.2 & 62.8 \\
Rust fontein 188 & 1247.0 & 1192.4 & 95.6 \\
Rust-fontein 234 & 777.8 & 413.0 & 53.1 \\
Sidoi 18311 & 324.0 & 310.9 & 95.9 \\
Snowdon 91 & 1281.4 & 1232.7 & 96.2 \\
South brook 320 & 552.3 & 550.3 & 99.6 \\
Stryd fontein 186 & 980.4 & 512.6 & 52.3 \\
Strydfontein 189 & 1042.9 & 922.9 & 88.5 \\
The hague 17819 & 785.8 & 601.2 & 76.5 \\
Tiger hoek 193 & 1147.4 & 1074.6 & 93.7 \\
Tramore 348 & 1224.7 & 1120.8 & 91.5 \\
Tramore 98 & 1564.9 & 684.6 & 43.7 \\
Umgano 18312 & 1265.5 & 458.5 & 44.0 \\
Weltevrede 17040 & 507.8 & 223.5 & \\
\hline & & & \\
\hline
\end{tabular}

The ability to rapidly identify farms affected and the extent to which each farm is burnt allows for disaster management response teams to identify critical farms in need of financial assistance. Rural and farming communities affected by the wildfire in KwaZulu-Natal were unable to cope with the impact of the fire using their own resources. Immediate intervention was needed to assist victims for the remainder of the season and to provide fodder for the surviving animals. Satellite remote sensing thus plays an integral part in the disaster response stage by identifying farms and communities affected by natural disasters such as wildfires.

\section{Conclusion}

The aim of this paper was to assess the potential of the new Landsat 8 multispectral data in mapping wildfires in KwaZulu-Natal. The following conclusions can be drawn:

1) Landsat 8 data successfully mapped burnt and unburnt areas with an overall classification accuracy of $93.33 \%$ and a $k$ statistic of 0.87 using a maximum likelihood classification algorithm on an independent test dataset.

2) The iso cluster algorithm also performed fairly well with a classification accuracy of $80 \%$ and a $k$ statistic of 0.67 on an independent test dataset.

3) Maps of farms and communities affected where created for disaster response teams in order to aid with emergency efforts and identify farms in need of critical assistance.

This study indicated the operational use of the new multispectral Landsat 8 data in disaster management. The result is critical for fire scar mapping in South Africa using freely available multispectral imagery. 


\section{References}

Bastarrika, A, Chuvieco, E and Martín, MP 2011, 'Mapping burned areas from Landsat TM/ETM+ data with a twophase algorithm: Balancing omission and commission errors', Remote Sensing of Environment, vol. 115, no. 4, pp. 1003-1012.

Bourgeau-chavez, LL, Kasischke, ES, Brunzell, S, Mudd, JP and Tukman, M 2002, 'Mapping fire scars in global boreal forests using imaging radar data', International Journal of Remote Sensing, vol. 23, no. 20, pp. 4211-4234.

Congalton, RG and Green, K (Eds.) 1999, Assessing the accuracy of remotely sensed data: Principles and practices, Boca Raton, FL, Lewis.

ESRI, 2010, 'ArcMap 10’, ESRI (Environmental Systems Resource Institute), Redlands, California.

Eva, H and Lambin, EF 1998, 'Burnt area mapping in Central Africa using ATSR data', International Journal of Remote Sensing, vol. 19, no. 18, pp. 3473-3497.

Guha-Sapir, D, Below, R and Hoyois, P 2014, 'EM-DAT: International Disaster Database', Université Catholique de Louvain Brussels, Belgium.

Hudak, AT and Brockett, BH 2004, 'Mapping fire scars in a southern African savannah using Landsat imagery', International Journal of Remote Sensing, vol. 25, no. 16, pp. 3231-3243.

Joyce, KE, Belliss, SE, Samsonov, SV, Mcneill, SJ and Glassey, PJ 2009, 'A review of the status of satellite remote sensing and image processing techniques for mapping natural hazards and disasters', Progress in Physical Geography, vol. 33 , no. 2, pp. 183-207.

Landmann, T 2003, 'Characterizing sub-pixel Landsat ETM+ fire severity on experimental fires in the Kruger National Park, South Africa', South African Journal of Science, vol. 99, July/Aug, pp. 357-360.

Lentile, LB, Holden, ZA, Smith, AMS, Falkowski, MJ, Hudak, AT, Morgan, P, Lewis, SA, Gessler, PE and Benson, NC 2006, 'Remote sensing techniques to assess active fire characteristics and post-fire effects', International Journal of Wildland Fire, vol. 15, pp. 319-345.

Mans, PH 2014, 'Veld fire assessment report for KwaZulu-Natal-June 2014', Cedara, Agriculture, Environmental Affairs and Rural Development.

Pereira, MC and Setzer, AW 1993, 'Spectral characteristics of fire scars in Landsat-5 TM images of Amazonia', International Journal of Remote Sensing, vol. 14, no. 6, pp. 2061-2078.

Petropoulos, GP, Kontoes, CC and Keramitsoglou, I 2012, 'Land cover mapping with emphasis to burnt area delineation using co-orbital ALI and Landsat TM imagery', Remote Sensing of Environment, vol. 18, pp. 344-355.

Prasad, AM, Iverson, LR and Liaw, A 2006, 'Newer classification and regression tree techniques: bagging and random forests for ecological prediction', Ecosystems, vol. 9, no. 2, pp. 181-199.

Roy, DP and Landmann, T 2005, 'Characterizing the surface heterogeneity of fire effects using multi-temporal reflectance wavelength data', International Journal of Remote Sensing, vol. 26, no. 19, pp. 4197-4218.

Trigg, S and Flasse, S 2000, 'Characterising the spectral-temporal response of burned savannah using in situ spectroradiometry and infrared thermometry', International Journal of Remote Sensing, vol. 21, no. 16, pp. 3161-3168.

Trigg, SN, Roy, DP and Flasse, S 2005, 'An insitu study of the effects of surface anisotropy on the remote sensing of burned savannah', International Journal of Remote Sensing, vol. 26, no. 21, pp. 4869-4876.

USGS, 2014, Landsat Missions, United States Geological Survey, viewed December 2014, $<\underline{\text { http://landsat.usgs.gov/band_designations_landsat_satellites }>\text {. }}$. 